\title{
The Analysis on Crowd Funding in China
}

\author{
Xuanting Liu \\ College of business Administration, University of Nebraska Lincoln, Lincoln, 68508, United States
}

liuxuanting1022@gmail.com

Keywords: Crowd Funding, Finance, Investment, Debt.

\begin{abstract}
This paper focus on the analysis on Crowd funding in China. Crowd funding is a new financial model aiming to fund a business or a project venture through the Internet. The advantage of crowd funding which includes the fact that it can raise finance very fast without requirement of upfront fees, the investors and donors are capable of tracking the process of the funded project, and it is a good advertising platform offer people get benefits. The disadvantages of listing in crowd funding, such as not all projects are able to successfully obtain funds through crowd funding. Usually, there is great need for high levels of campaign in order to create interest before the project is launched. In China, there are two mainly crowd funding platforms appeared which are rewardbased crowd funding and equity crowd funding platforms. Through compare two different types of platform, equity crowd funding is most popular than other. In China, there are no stated national regulations regarding any form of crowd funding so that it cannot develop fast, but it will increase in the near future meet the needs of Chinese economy.
\end{abstract}

\section{Introduction}

Crowd funding just like public financing, which is a pre-consumption model, with the "buy plus pre-order" form to raise funds to the public project. The use of the internet and SNS to raise the spread of the characteristics of small businesses, artists or individuals to public to show their creativity, thereby striving for everyone's attention and support, and then get necessary financial assistance. Crowd funding refers to the process of raising funds by means that target many people especially through the internet. The aim is to fund a business or a project venture through several donors. Essentially, it involves steps of raising capital for charity or business project through a combined effort of family, friends, investors and customers (Kirby and Worner 15). This way, the method taps a larger pool of different individuals for a greater exposure and wide reach. It uses the internet through platforms that target a wide range of people. Some of these platforms include the Kickstarter, crowd funder and Indiegogo. In these platforms, the level of fundraising is defined with rules and fees varying across platforms (Barnett 33). The online platforms provide an opportunity to the fundraiser to design a public campaign program that is aimed at calling for donations from different donors. The focus is to design a convincing strategy so that the nature of the venture or the project can get the attention of potential donors. Through the campaign, the project is advertised while stating other aspects such as the amount of money that the company intends to raise and the deadline for the fundraising.

In today's society, why Chinese people need to develop crowd funding? In the fierce competition market in China, the individual resources are always limited, all kinds of advantages resources need to be aggregated, therefore, crowd funding is a way to build up. For the entrepreneurs, crowd funding is an excellent opportunity, through crowd funding, you can fully mobilize all the resources around, it is easy operating for the venture projects. Crowd funding is all the public can participate in. Crowd funding is not only a collect money, but also, it's the use of information network, and the various advantages of resources. What's more, it also a kind of business model to explore the future way of life and people's vision. In simpler terms, crowd funding is not just a platform, it is a business model, an idea, even though is a lifestyle. Crowd funding have an important role in helping 
individuals and enterprises. In this era of innovation, crowd funding is a shortcut to successful business.

The rest of the paper is organized as follows. Section 2 presents the pros and cons of crowd funding in the first part. Crowd funding's advantages can give people more suggestions in future's investment. Every coin has two sides, people often only care about the good side of the idea but ignore its shortcomings, I analyze the shortcomings of crowd funding in order to make people realize this. In the Section 3, It is presenting the types of crowd funding and the characters of each type. Section 4 analyzes the Condition of Chinese Crowd Funding. Through some data to analyze different types of crowd funding: changes in platforms, which type has the highest platforms growth rate; In the different region, which province has preferred to use crowd funding platforms; and in the different work field, which part is easier to invest in crowd funding. Lastly, in the Section 5, it presents the important part in the paper which is the prospect of the Chinese Crowd funding.

\section{The Advantages and Disadvantages of Crowd Funding in China}

Crowd funding has both advantages and disadvantages. Its advantages include the fact that it can raise finance very fast without requirement of upfront fees. Also, pitching the project or business idea through the online platforms makes it a valuable type of marketing strategy due the mass media attention created. Sharing the idea to many people makes it possible to get expert feedback and guidance. This is fundamental to the establishment of the best ways of project improvement. This also provides an opportunity to test the reaction of the public regarding the project or the idea. Therefore, its viability can be established based on how people respond to the campaign. The other advantage is that investors and donors are capable of tracking the progress of the funded project and hence helping in brand promotion through their wide networks. In addition, investors may become among the most loyal clients and customers to the resulting product due to their involvement in the financing process. This method of financing is therefore, a good alternative to the traditional sources of finance such as the hard to get and expensive bank loans. Finally, crowd funding is a good advertising platform. This is reflected in two points. First, the success of your project financing, which is equivalent to a public advertising, Some people see your project but did not contribute money, it may be because people cannot determine whether you will be able to produce enough money to produce this product. However, once you have enough money helps by others, they will be your future clients. Second, regardless of whether the financing is successful, your project has been displayed. Then, your project will show to your potential investors. In Shushu's paper the development of crowd funding model, the trend of supervision and the enlightenment to China, she said that the rapid development of crowd funding has effectively alleviated the financing difficulties of small and medium-sized enterprises, especially start-ups, and has provided new channels for SME financing. It has played an active role in promoting employment and economic development objectively.

However, crowd funding comes with several disadvantages. For instance, it is not necessarily an easy way to finance ventures through crowd funding. In essence, not all projects are able to successfully obtain funds through crowd financing. Also, all investors on a crowd funding platform is not specific enough. Crowd funding platform can help you quickly get used to the product development and production funds, but it cannot guarantee your future financial chain intact. After traditional venture capital investment in to early, if the project is developing smoothly, you also have access to follow-up funding. On the crowd funding, your supporter is likely to have already turned their attention to other novel inventions. In addition, while in the selected platform, there is great need for high levels of campaign in order to create interest before the project is launched. This requires significant amounts of resources such as money and time. Attempts may fail to raise adequate funds for the project. In such circumstances, the collected funds are returned to the investors and donors without any gain from the venture. In addition, if projects fail, the business reputation is damaged. Also, the massive exposure of business ideas may lead to infringement of copyright or patent rights where some people may steal the idea and the concept. 


\section{Crowd Funding Platform Types in China}

Crowd funding started late in China, but it has developed rapidly. In 2011, Chinese first crowdfunding platform "named time" was set up. At present, there are dozens of crowd funding platforms, such as reward-based crowd funding and equity crowd funding. The scale of financing is expanding, the operation process is becoming more and more standardized and the experience is accumulating. In the development of Chinese economy, there are several kinds of ways of raising capital for business projects in the different stages of such business growth. Similarly, there are varieties of crowd funding types that can be utilized in financing different stages of project's life cycle. The method of crowd funding selected depends on the product or service being offered and the personals goals for the product growth. Some of the main types of crowd funding include donation-based, equity-based and reward based crowd funding techniques (Mollick 54). There can also be debt crowd financing where investors expect to receive their funds back with some interest. This is a kind of peer to peer lending hence bypassing the role of traditional banks. Even though it creates some financial returns to the investors, they also benefit by having the opportunity to participate in the realization of an idea that they believe in.

Equity crowd funding refers to the company to sell a certain percentage of the shares to ordinary investors. Investors use by investing in shares of the company and access to future earnings. Equity crowd funding is among the traditional ways of financing projects by making funders part owners of the business. This is enhanced by trading equity shares in exchange for capital. Investors in this case receive financial returns to their investment and eventually receive share of the company profits through distributions or dividends.

There are several equity crowd funding operating modes in today's China. First is certificate crowd funding. The certificate mode is mainly referring to raise equity by selling vouchers and bundled form on the internet, investor pay money to obtain the relevant certificate, the certificate is directly linked to the equity of the venture or project, but the investor is not a shareholder. Second is membership crowd funding. This is referring to the internet through acquaintances introduced, the investor pay the funds directly into the shareholders of the invested enterprise. Last one is "Angel crowd funding”. Different form the certificate and membership mode. Angel crow funding closer to angel investment or Venture capital. Investors look for investment enterprises or projects through the internet, or pay the money directly or indirectly become shareholders of the company, at the same time, investors are often accompanied by some clear financial returns.

The reward-based crowd funding is the other type of this approach that involves contributions of individuals towards a business project in exchange for rewards in form of products or services offered by the company. This is a form of donation-based crowd funding because even though there are backings in form of rewards, there is no equity or financial return. This approach is very popular because it allows businesses and their owners to incentivize their contributors without incurring any extra expenses or without selling of the business ownership. On the other hand, donation-based crowd funding is more of campaigns in order to source funds without any financial return to the donors, contributors or investors. Therefore, in this sense, the campaign involves creating an appeal to different people so that they can pay attention to the project and hence direct their monies towards financing several initiatives such as fundraising for charities, disaster relief, medical bills and nonprofits among other aspects where the main motive is not investment for a financial return but to participate by bringing their financial help to the society. This is different form of crowd funding compared to reward-based and equity based crowd funding approaches. There are five characteristics of reward-based crowd funding.

- Found Creativity

All crowd funding in the forefront of the industry chain, you can quickly find and explore potential product projects.

- Needs Verification

Through the user to get real money to vote, you can verify the project id in line with market demand, greatly reducing the risk of project failure. 
- Fans Getting

It provides a natural roadshow platform to help the originator of the first batch of loyal fans.

- Finance Endorsement

After all the data of results in crowd funding, the project will provide the most powerful explanation for the future financing.

- Financing Cooperation

All the crowd funding base on the performance of the project financing date, providing loans, incubation or investment and other financial services.

Essentially, crowd funding is the opposite of other mainstream sources of business finance. The traditional approaches involved coming up with a business plan and a high level of market research so as to sell the idea to different funders. There were also incidences of testing the prototype in order to attract these funders who comprised of few wealthy individuals and institutions. The funding sources included banks, venture capital firms and angel investors. This was a kind of a fixed approach with a limited pool of potential funders. On the other hand, crowd funding focuses on a wide range of potential funders in an open approach so that the entrepreneur can be able to showcase, built, and share pitch resources. This way, the project is made public through campaigns and advertisements. The owner of the project has only one thing in mind: obtaining financial resources for the project of business venture. The massive campaigns through the established online platforms are likely to attract many potential investors or donors who might be interested in participating in provision of finances towards realization of the stated project. This is the differentiating characteristic of crowd funding from the traditional approaches.

\section{The Condition of Chinese Crowd Funding}

In a research paper "Current development situation of financing mode in China and foreign countries and suggestions for Chinese development" wrote about that, crowd funding in our country mainly have four types, which are reward crowd funding, public interest crowd funding, equity crowd funding and bonds crowd funding. The rise of all crowd funding have great significance in Chinese investment and financing model innovation and Internet financial innovation (Wen Bo). Due to these four types of crowd funding, there are four charts can easy to explain Chinese situation in crowd funding.

From Figure 1, this is a combination graph which include curve graph and bar chart. The curve graph shows the trend of numbers of crowd funding platform from March 2015 to December 2016. The bar chart shows growth rate in every month. Overall, the number of crowd funding platforms increases rapidly in China in the recent years. From April 2015 to June 2015, the number of platforms have more growth. Thus, it can be seen, the rapid development of Chinese economy, companies have begun to expand the operation scale, in this case, the source of funds has become the mainly problem of each company's development. In order to solve this problem, crowd funding as a kind of financing mode began to appear and play an important role. However, from March 2016 to December 2016, the growth rate almost constant. In the recent year, more people know to Crowdfunding, but there are no clear legal forms to manage crowd funding, so that some criminals utilize crowdfunding in illegal collect money, therefore, the growth rate was decreased. 


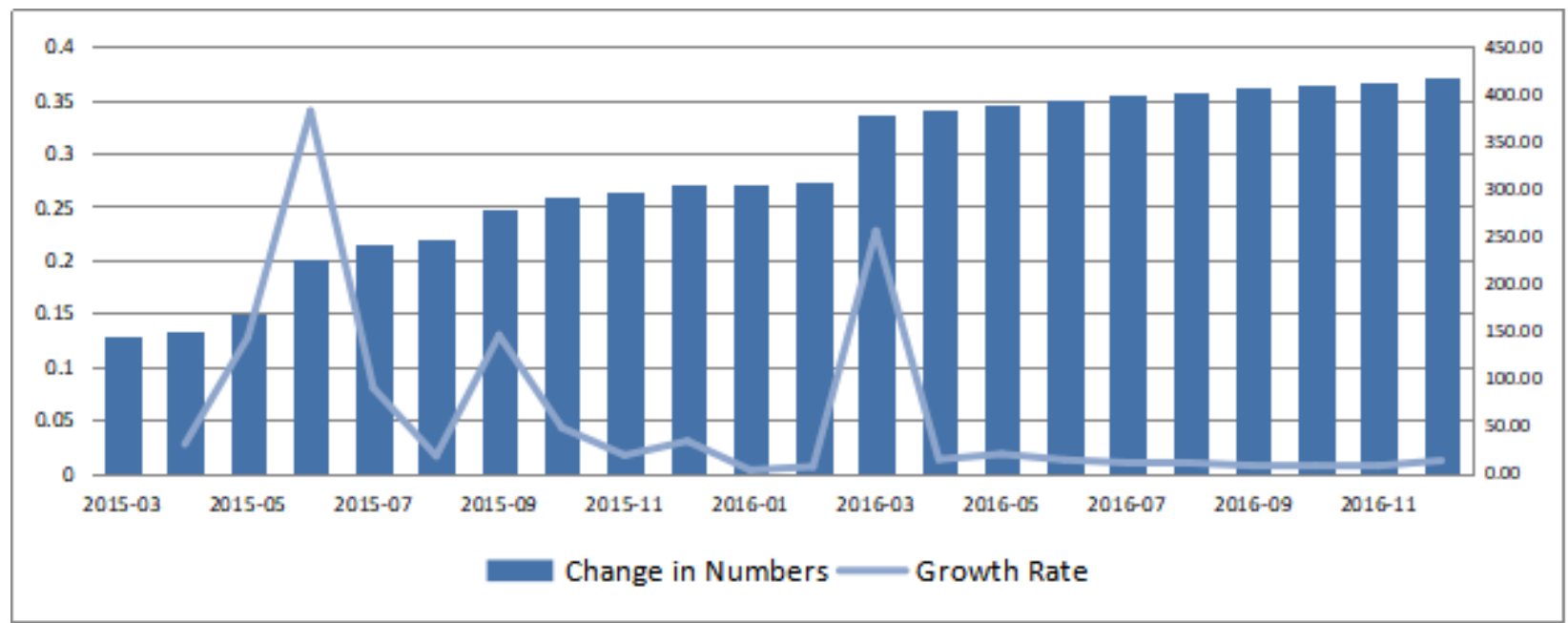

Fig. 1 Changes in number of types of Crowd Funding Platforms

According the Figure 2, the table shows the changes in the number of types of crowd funding platforms over the period from March 2015 to December 2016. All the number of two types of crowd funding platforms increases year by year. From March 2015, these two types of crowd funding platforms have the same numbers of platforms until May 2015. After that, the number of equity crowd funding exceed the reward-based crowd funding until December 2016. According to this result we know that Chinese people prefer the type of equity crowd funding. The biggest feature of equity crowd funding is diversity, more is to raise money for the purchase of the company's equity. Equity crowd funding can be divided into many types of segments in China, such as some crowdfunding platform focused on sustainable development of the Internet, O2O, high-end technology direction, and improved the future value of entrepreneurial companies, people can get dividends through equity platform. However, the reward-based crowd funding is preferring to business, so the reward-based crowd funding should be a commercial gift. Commercial gifts are generally for the sale product, it has a dual nature and compensation. Consequently, people prefer to get benefit easily through equity crowd funding. In a paper the condition of Chinese Crowd funding mentioned, Reward-based crowd funding in the Internet as a financing platform, not in return for fund, but equity crowd funding is equity investor are raising a certain proportion of the company's share. For the majority of investors to raise funds, investors eventually equity realized or dividends in the form of income(Xiaojun \& Jun).

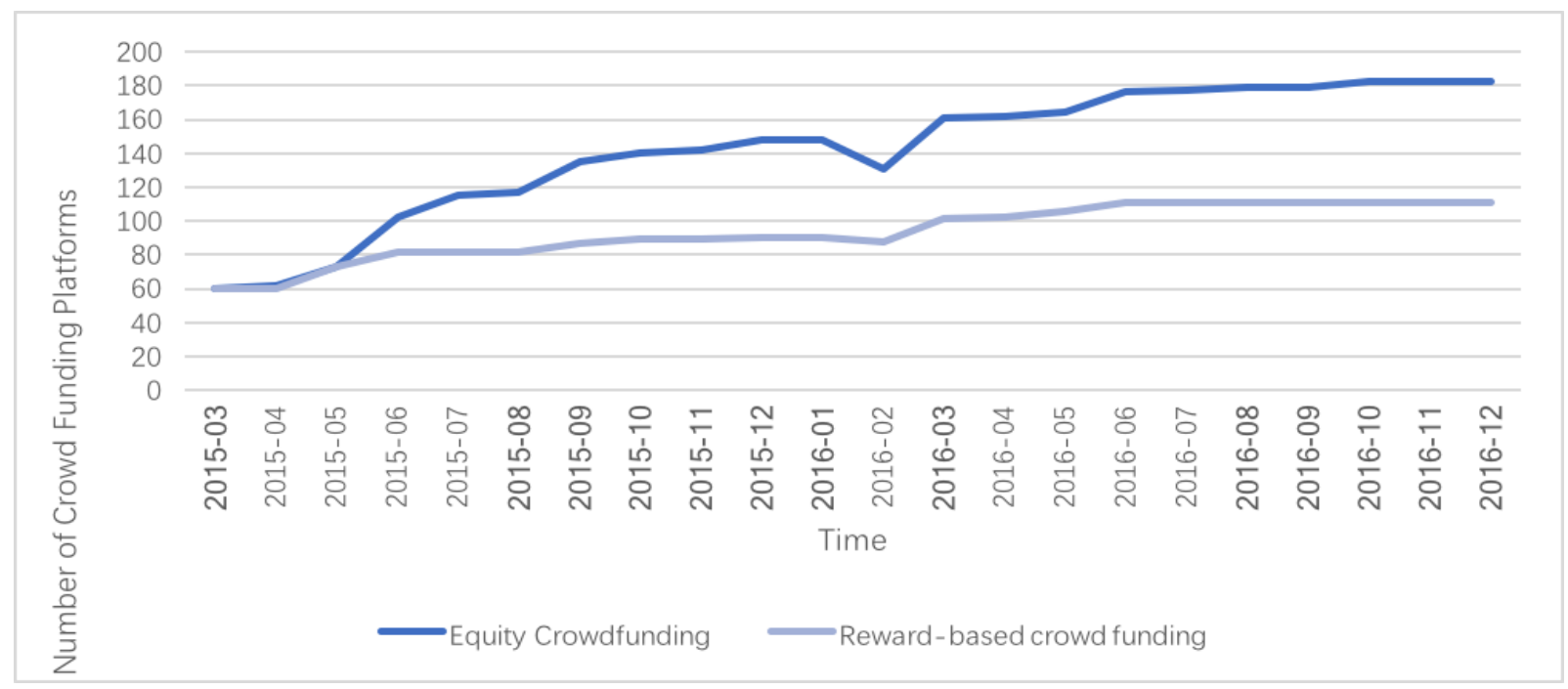

Fig. 2 Comparison with types of Crowd Funding

Figure 3 shows numbers of crowd funding platforms change in the different region. As you can see, in general, coastal cities tend to grow faster than inland cities. Beijing as the capital of China is 
having higher-than-desirable growth rate. Beijing has developed technology, advanced facilities and biggest population. The number of platforms in Henan province remained almost unchanged between 2014-07 to 2016-12. However, Shanghai as a financial center in China, the number of platforms growth is not as good as Guangdong province. Shanghai just because of the financial center, there are many investment ways to money management so that crowd funding is not popular. Crowd funding has certain risks, people rather choose more safe investment way than crowd funding.

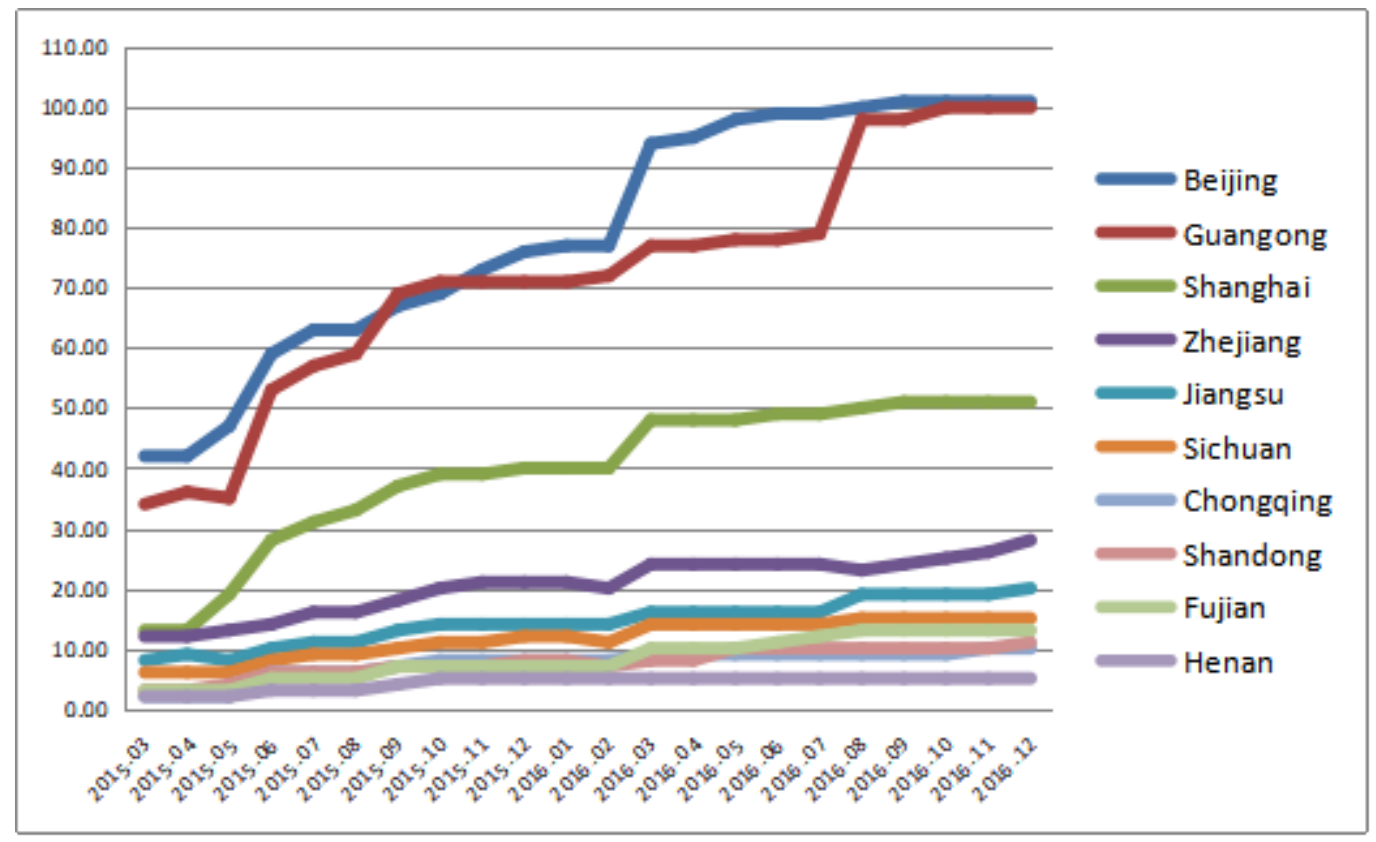

Fig. 3 Change in the different work field

From Figure 4 which is a Pie chart, this chart shows how many people invest non-equity crowd funding in the different work field, such as technology products, agriculture, design, food, commonweal, art, film and published books. It cleared to see that technology products have the biggest share in the pie chart. Next one is agriculture. Film and published books make up the smallest proportion. In the recent year, people rely on new technology more than previous years. With the popularization of the overall level of education and promotion of mobile internet, as a new generation of 90s youth groups representatives, investment banking through the internet is becoming a popular way, from simple monetary fund management to equity fund financing, and then to direct investment in the stock market, the younger generation groups often choose the easy and convenient way to complete through the internet. For the fund companies, securities companies or other financial institutions, who meets the needs of young people, who really has the future. As a generation growing up with the development of internet, 90s has used the internet brings convenience to people, especially mobile internet. They trust in internet is much higher than their parents, is to abandon the traditional financial and to favor the internet financial. Therefore, that is why more people invest technology products than other fields. Technology products are easier access to investment returns. As I mentioned before, young people are more dependent on the internet so that abandon books. Although some people like reading books, there are many eBooks Apps on the internet or mobile phone. Published books are not popular today, it is hard to see the benefits if the people invest this field. 


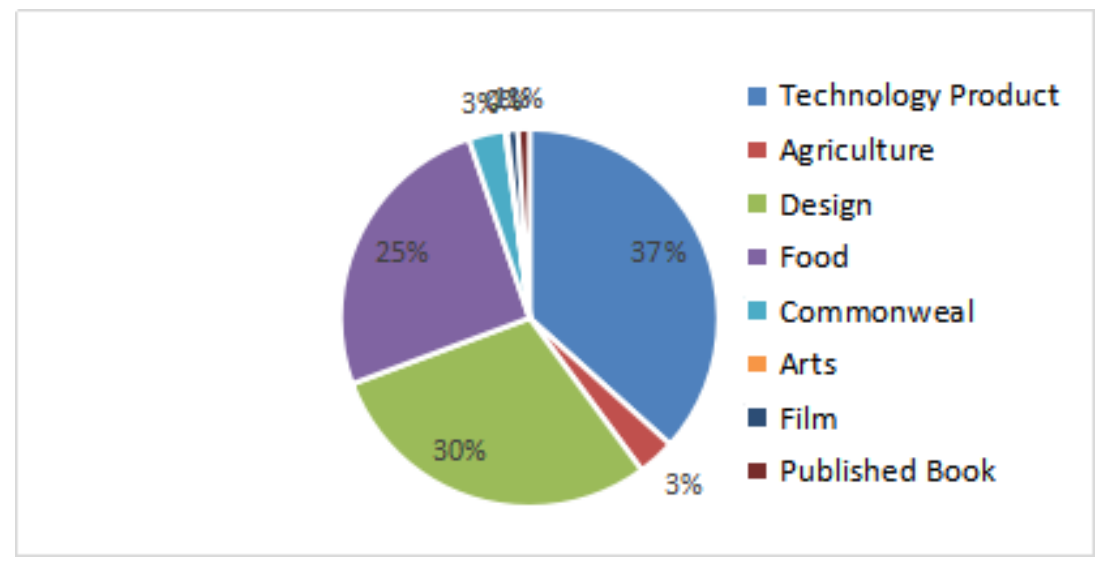

Fig. 4 Number of Investment - Percentage in Different Field From2015-06 to 2016-12

\section{The prospect of the Chinese Crowd funding}

The prospect of crowd funding in China can be established through market analysis of such internet source of finance. Crowd funding in China is a new concept and has not been highly adopted when compared to the other mature markets like the United States (Zheng et al. 488). These differences result due to diversity in terms of government regulation. In the United States, the government regulation encourages use of equity-based crowd funding. However, in China, oversight body and government have no stated national regulations regarding any form of crowd funding. As a paper mentioned before, In China, whether equity crowd funding or other types crowd funding are involved in illegal funding-raising. Although the crowd funding through the nature of different channel on the website of the relevant statement made, crowd funding is not same as with the traditional investment and financing, because investors cannot obtain equity, profit sharing return here. People are in the purchase of finished products, not investment product. According to Chinese relevant laws and regulations to measure, no matter how it is explained, still can be suspected of illegal fund-raising(Jianying).

These differences in the regulatory framework reinforce other differences with regard to investment culture and experience within each particular country. In a Chinese research paper " $A$ case study reveals the development of domestic crowd funding" mentioned, "In China, the development of crowd funding investors still have a series problems, such as poor liquidity, no dividends, dilution of equity, and failure of invested enterprises. Also, because there is no domestic environmental legal support to crowd funding, equity crowd funding platform development is restricted, there are many platforms and projects are “aborted”(Ronghao). At present, China's public crowed funding to raise the business model includes lead investors-with the investment model, investment model, direct investment model. Represented by these models to raise public crowd funding platform in China has been rapid development. The biggest dilemma in the process in China's rapid development is the legal obstacles. Participation in the equity of the public to raise the interest of enterprises and investors can not be recognized and protected by law, which contains a huge risk and hidden danger, it has caused great concern in the market and the government.

China has many projects that are in great need of capital investment. This is due to the presence of many incidences of innovativeness and creativity that result to viable business ideas and projects. There is a very big gap in terms of capital demand for new businesses that seek fundraising in China. This shows that the potential capital supply in China through crowd funding has a higher chance of increasing because many Chinese are shifting from savings to investment-orientation. Increased investment opportunities are more likely to necessitate different types of funding. Crowd funding will be on an increase once people in China start realizing the advantages associated with the use of this financing strategy. Therefore, it can be concluded that prospectively, crowd funding in China is likely to increase in the near future. This is justified by the increased possibilities of new business ventures and other activities in need of capital in China. Inadequate traditional approaches to 
financing such projects will lead to increased use of alternative approaches. The only viable alternative will be the crowd funding approach in China.

\section{Conclusion}

According to the description of the whole article, it introduces and analyzes crowd funding in China. Firstly, we know that crowd funding through the United State Kickstarter platform introduced into Chinese new investment financial platform. However, due to the development of Chinese economy, there are advantages and disadvantages. The most important advantage impact Chinese economy are the investors and donors are capable of tracking the process of the funded project, and it is a good advertising platform offer people get benefits. For the disadvantage, as Chinese does not have specific laws and regulations to regulate the crowd funding platform, there are many criminals will raise illegal fund-raising through crowd funding. Therefore, based on this problem government should take measures. Secondly, there are two main crowd funding platform types in China at present, which are equity crowdfunding and reward-based crowdfunding. According to compare two different platform types data, Chinese people prefer the type of equity crowd funding. The biggest feature of equity crowd funding is diversity, more is to raise money for the purchase of the company's equity. Lastly, the prospect of crowd funding in China can be established through market analysis of such internet source of finance. Although crowd funding is a new concept right now, because of its diversification, the future development must be more rapid, what's more, it also will receive more people's attention.

\section{References}

[1] Barnett, Chance. "Donation-based crowdfunding sites: Kickstarter vs. Indiegogo." (2013).

[2] Kirby, Eleanor, and Shane Worner. "Crowd-funding: An infant industry growing fast." IOSCO, Madrid (2014).

[3] Mollick, Ethan. "The dynamics of crowdfunding: An exploratory study." Journal of business venturing 29.1 (2014): 1-16.

[4] Zheng, Haichao, et al. "The role of multidimensional social capital in crowdfunding: A comparative study in China and US” Information \& Management 51.4 (2014): 488-496.

[5] Wenbo. "Current development situation of financing mode in China and foreign countries and suggestions for Chinese development.” Internet Economy (2015): 254-8.

[6] Ronghao, “A case study reveals the development of domestic equity crowd funding.” Financial Law Forum (2014).

[7] Xiaojun Ren \& Jun He "The condition of Chinese crowd funding" Theoretical exploration (2016): 218-2

[8] Jianying Chen, “Chinese crowd funding model's problem and countermeasures of the mode of existence.” Journal of Hunan Finance and Economics University (2015): 158-31.

[9] Shushu Liu, "the development of crowd funding model, the trend of supervision and the enlightenment to China.” Journal of Finance and economics (2014): 07-0047-05. 